\title{
Periosteal new bone formation in Klippel- Trénaunay syndrome: a case report
}

\author{
Xiang Fang ${ }^{1 \dagger}$, Wenli Zhang ${ }^{1 \dagger}$, Zeping $\mathrm{Yu}^{1}$, Fuguo Kuang ${ }^{2}$, Bin Huang ${ }^{3}$ and Hong Duan ${ }^{1 *}$
}

\begin{abstract}
Background: Klippel-Trénaunay syndrome (KTS) is a complex congenital vascular disorder, typically accompanied by port-wine stains, varicose veins, and limb hypertrophy. This paper reports a rare and unusual clinical condition of periosteal reaction in a pediatric case of KTS. Although periosteal new bone formation is not rare in children, as is KTS, their dual occurrence or the presentation of the former due to KTS has not been previously documented. Our objective in this study is to highlight the potential association between periosteal new bone formation and KTS, as well as to help physicians consider this association when bone neoplasm has been ruled out.

Case presentation: A 7-year old girl, initially presented with a persistent mild swelling in her left shank, with no abnormalities in the X-ray of the tibiofibular. However, after a few consults and examinations, 7 weeks later, a $17 \mathrm{~cm}$-long periosteal new bone formation along the left tibia and diffused dilated vessels in the left shank were revealed by the radiological examination. Not knowing the true nature of the fast-growing lesion in a typical case of KTS was worrying. Therefore, a core needle biopsy was performed. The test demonstrated a possible parosteal hemangioma. Following further investigation through an excisional biopsy, and a pathological analysis, hyperplasia of the bone tissues with no tumor cells was revealed. Thereafter, an elastic stocking treatment was prescribed. During the first two-year follow-up, recurrence of the mass or sign of progression of KTS was not observed.

Conclusions: Periosteal new bone formation is a potential manifestation of KTS. Based on the conclusive pathological results of the excisional biopsy, invasive examinations and surgeries could be avoided in future KTSsubperiosteal lesion manifestations.
\end{abstract}

Keywords: Bone tumors, Children, Definite diagnosis, Periosteal reaction

\section{Background}

Klippel-Trénaunay syndrome (KTS) in childhood is well-documented and commonly characterized by portwine stains, varicose veins, and the overgrowth of long bones and soft tissues [1, 2]. In this report, we describe an atypical pediatric case of KTS, in which a $17 \mathrm{~cm}$-long periosteal new bone formation of the tibia developed rapidly within 7 weeks. Periosteal new bone formation is very common in pediatric bone neoplasm, especially bone malignancy; however, it rarely occurs in cases of KTS. Therefore, this presentation has not been described in extant KTS-related literature. Our objective in this study is to highlight the potential association between periosteal new bone formation and KTS, as well as to help physicians consider this association when bone neoplasm has been ruled out.

\section{Case presentation}

A 7-year old girl presented to the local hospital with mild swelling in her left shank that had persisted for one week. A radiograph of the tibiofibular showed no abnormalities (Fig. 1), and a herbal remedy for external use

\footnotetext{
* Correspondence: duanhong1970@126.com

Xiang Fang and Wenli Zhang contributed equally to this work, and they are co-first authors.

${ }^{1}$ Department of Orthopedics, West China Hospital, Sichuan University, 37 Guo Xue Lane, 610064 Chengdu, Sichuan, People's Republic of China

Full list of author information is available at the end of the article
} 


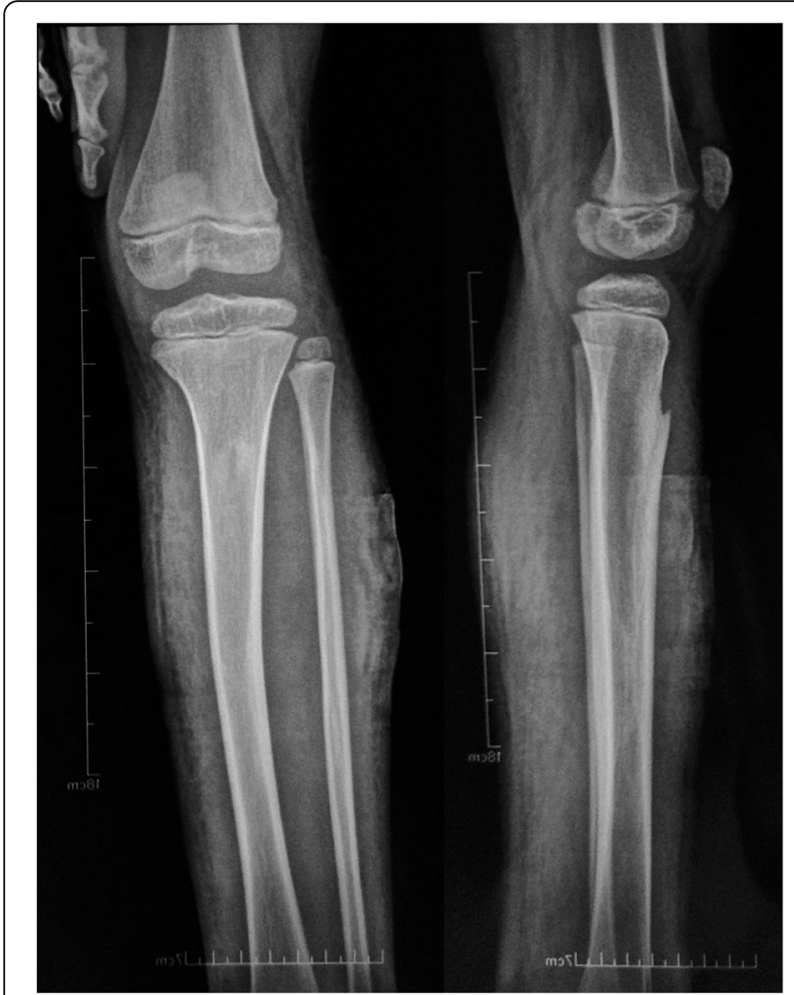

Fig. 1 Initial radiograph of the tibiofibular shows no abnormalities was applied. One week later, the shank swelling aggravated, and she presented to our hospital. On examination, apart from the swollen shank, we also observed multiple port-wine stains and limb overgrowth (longer extremity and larger foot). Ultrasonography revealed great/lesser saphenous vein thrombosis in the lower left leg and an ill-defined hypoechoic mass containing flaky hyperechoic foci near the left tibia. Based on the aforementioned findings, a clinical diagnosis of KTS was established. The use of low-molecular weight heparin and mucopolysaccharide polysulfate cream was initiated.

The patient re-admitted 6 weeks later, reporting a palpable hard mass in the anterolateral left shank and complete resolution of the swelling. Radiological examination revealed a $17-\mathrm{cm}$ periosteal new bone formation along the left tibia and multiple dilated vascular structures in the left shank (Fig. 2). Coagulation status was normal. No fever, allergies, severe pain, or a recent history of trauma were presented.

Bone neoplasm was first suspected but subsequently ruled out due to the regular pattern of periosteal new bone formation without soft tissue mass, bone destruction, and symptoms. However, concerning the fastgrowing lesion in KTS, we performed a core needle biopsy, which revealed a possible parosteal hemangioma. Consequently, an excisional biopsy of the lesion was performed and intraoperatively, only regularly thickened eggshell-like hard tissues and blood clots in the cavity of the lesion were found, Pathological analysis revealed

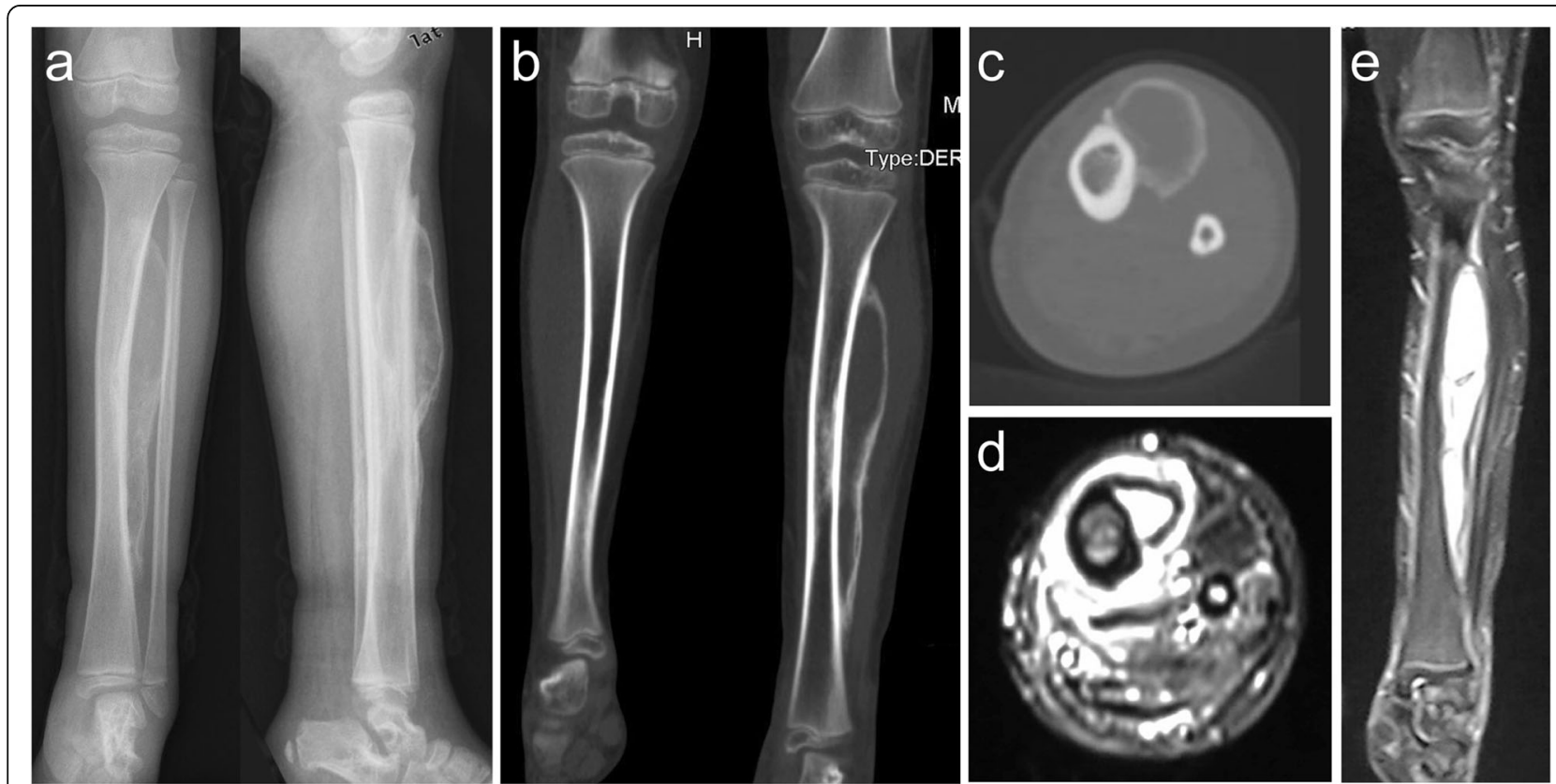

Fig. 2 Radiographs and computed tomography images of the tibiofibular (obtained 7 weeks after the initial radiograph) reveal a parosteal highdensity lesion with well-defined borders along the long axis of the left tibia $(\mathbf{a}, \mathbf{b}, \mathbf{c})$. T2-weighted magnetic resonance imaging scans of the lower legs show heterogeneous high-signal intensity in the anterolateral aspect of the tibia, with diffused dilated vessels in the left shank ( $\mathbf{d}$, e) 
hyperplasia of the bone tissues with cystic wall-like structures, old hemorrhage with hemosiderin deposition, and no tumor cells. Thereafter, an elastic stocking treatment was prescribed. During the first two-year followup, recurrence of the mass or sign of progression of KTS was not observed.

\section{Discussion and conclusions}

First described by Maurice Klippel and Paul Trénaunay in the year 1900, KTS is estimated to affect approximately one in 30 000-100 000 liveborn neonates [3-5]. It is a complex congenital vascular disorder accompanied by capillary malformation (port-wine stains), venous malformation (varicose veins), and overgrowth of the long bones and soft tissues, usually involving a single lower extremity [1]. Our patient was born with portwine stains from the abdomen to toes and minor limb discrepancy that became more apparent over time (Fig. 3).

The actual pathogenesis of KTS is not completely understood. A somatic mosaic mutation in phosphatidylinositol-4,5-bisphosphate 3-kinase catalytic subunit alpha (PIK3CA) is hypothetically a major potential cause of KTS [6]. However, other factors, including the mutations in the angiogenic factor with $\mathrm{G}$ patch and FHA domains 1 (AGGF1), Ras p21 protein activator 1 (RASA1), and Krev interaction trapped 1 (KRIT1) genes, and alterations in the fetal mesoderm for intrauterine damage, may also be involved in disease pathogenesis [6-12]. However, our patient denied any intrauterine damage and her parents did not allow her to undergo gene mutation tests.

Typical KTS cases are diagnosed based on physical examination findings without imaging, laboratory, or genetic testing [13]. However, it should be differentiated from Parkes-Weber syndrome-a high-shunt fast-flow arteriovenous malformation-by checking for the presence of a significant arteriovenous fistula. In our patient, the diagnosis was made based on her inborn port-wine stains, limb overgrowth, vasodilation in her right lower limb, as detected on MRI, and absence of an arteriovenous fistula in ultrasonography.

There is no cure for KTS; therefore, treatment is symptomatic. Nonoperative modalities play a major role in most symptomatic KTS patients. Compression and elevation are the fundamental bases for lower extremity chronic venous disease. Although patients with KTS are at an increased risk of thromboembolic events, anticoagulation therapy is not indicated in the early clinical course. However, it should be initiated following the presentation of deep venous thrombosis, like at the time of the first hospital presentation of our patient, or for prophylaxis during the perioperative course [14]. The absolute indications for operative vascular intervention are persistent

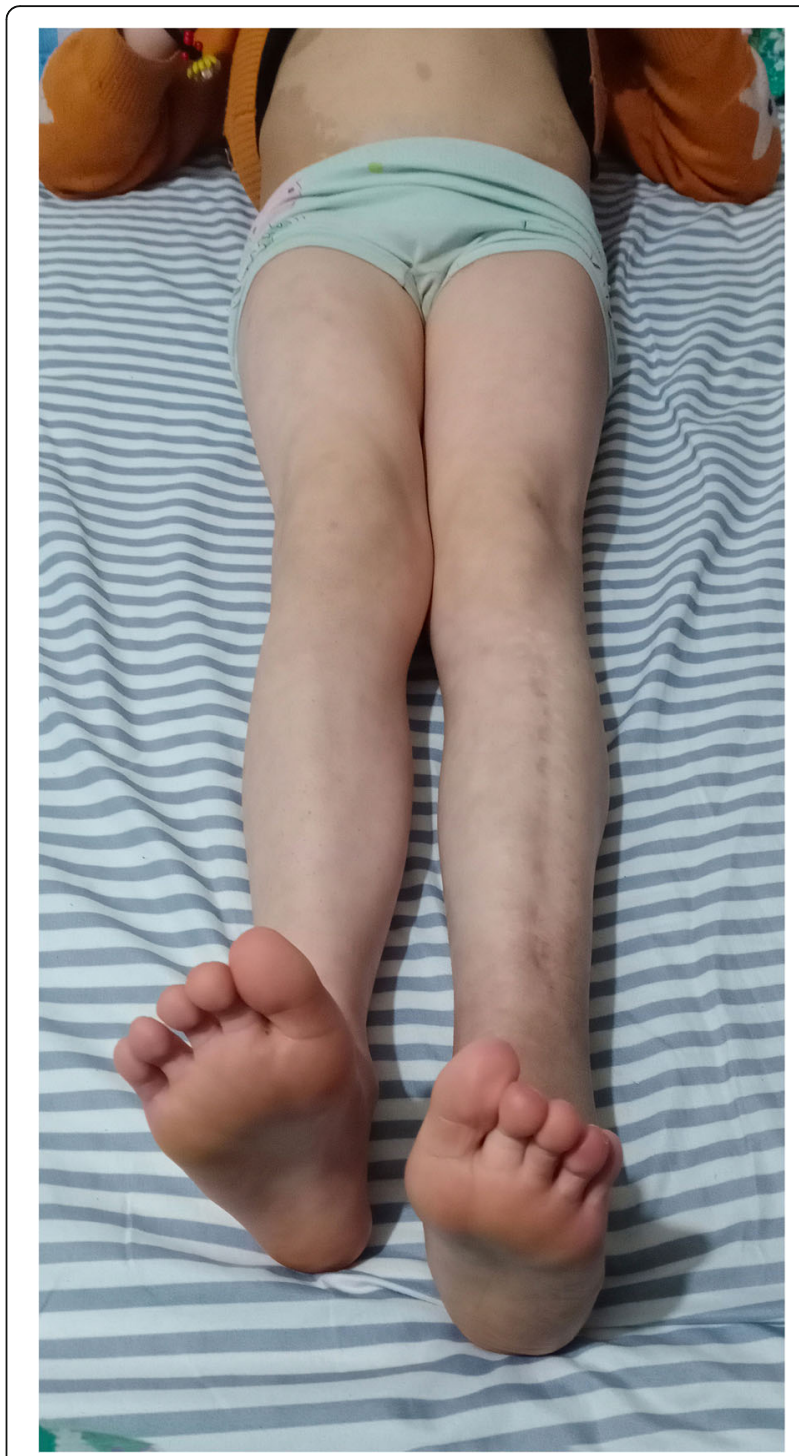

Fig. 3 Photograph of the patient (taken 2 years postoperatively) shows multiple port-wine stains and limb overgrowth

hemorrhage, acute thromboembolism, and refractory ulcerations, while the relative indications are pain, cosmetic, limb asymmetry, swelling secondary to venous insufficiency, and functional impairment [15]. When limb length discrepancy is $<1.5 \mathrm{~cm}$, heel inserts or compensatory shoes can be used to improve the limp and to avoid possible scoliosis. However, when the discrepancy is $>2 \mathrm{~cm}$, orthopedic osteotomy or epiphysiodesis should be considered [16]. Our patient had a mild form of KTS. She was mostly asymptomatic, even prior to the use of the elastic stocking. Despite the discrepancy in the limb length, she could walk and run normally, without limping, with heel inserts. However, as her limb overgrowth gradually became more apparent, she was constantly annoyed by her larger right foot when buying new shoes. 
Atypical clinical manifestations of KTS reportedly include hypersplenism, nephrotic syndrome, cerebral cavernous angioma, and puerperal hemorrhage [17-19]. Bone involvement in KTS is commonly noted and typically manifests as circumferential hypertrophy, longer extremities, ectrodactyly, polydactyly, syndactyly, camptodactyly, and clinodactyly, and in rare cases, intraosseous vascular malformation $[1,2,20,21]$. However, to the best of our knowledge, this report presents the first case of KTS with periosteal new bone formation.

Periosteal new bone formation, also called periosteal reaction, is a nonspecific response of the periosteum to underlying "irritation," which typically presents not only in patients with benign and malignant tumors, as well as osteomyelitis and thalassemia. A nonaggressive periosteal bone formation is usually slow-growing with thin, solid, thick and irregular, or septated imaging features, while fastgrowing masses with laminated (onion skin), spiculated (perpendicular/hair-on-end and sunburst), disorganized, and Codman triangle images are generally found in the aggressive periosteal reactions [22]. Our patient developed a rapidly enlarging osseous mass with nonaggressive periosteal new bone formation, thus not implying malignancy. However, the true nature of the lesion remained unknown before final excision, as there are reports on tumors detected in patients with KTS, including malignant peripheral nerve sheath tumors, angiosarcomas, astrocytomas, hemangiopericytomas, hemangiomas, and meningiomas [23-28]. Moreover, isolated hemihypertrophy, a major clinical manifestation of KTS, is a potential risk factor for developing neoplasms, although the risk of embryonal cancer is reportedly not higher in children with KTS [29-31].

The precise pathophysiology for the large periosteal new bone formation in KTS remains unknown to date. However, due to the KTS-related massive vascular malformation, we speculated that the spontaneous rupture or minor trauma of the diseased capillaries on the periosteum led to subperiosteal bleeding, which further lifted the periosteum. The new bone was suspected to generate by the periosteum; accordingly, bone tumor was suspected. Although a serious malignancy was not found in radiology, the fast-growing lesion in a typical KTS case still worried physicians. However, with definitive pathological results, invasive examinations and surgical interventions may be avoided for KTS patients with subperiosteal lesions in the future.

\section{Abbreviations}

KTS: Klippel-Trénaunay syndrome; PIK3CA: Phosphatidylinositol-4:5bisphosphate 3-kinasecatalytic subunit alpha; AGGF1: Angiogenic factor with G patch and FHA domains 1; RASA1: Ras p21 protein activator 1; KRIT1: Krev interaction trapped 1

Acknowledgements

Not applicable
Authors' contributions

Conception/Design: XF, HD, WLZ, BH; Provision of study material or patients: XF, ZPY, FGK; Collection and/or assembly of data: FGK, WLZ; Data analysis and interpretation: WLZ, BH; Manuscript writing: XF, WLZ; Final approval of manuscript: HD, ZPY, XF, WLZ, BH, FGK. These authors have reviewed the final version for the manuscript and approve it for publication.

\section{Funding}

The author(s) received no financial support for the research, authorship, and/ or publication of this article.

\section{Availability of data and materials}

All data generated or analysed during this study are included in this published article

\section{Ethics approval and consent to participate}

This study was conducted in accordance with approval from the Ethics Committee of West China Hospital (Chengdu, China). Written informed consent has been provided by the patient's father. And the father gave us full permission for the materials to appear in the print and online, and grant permission to third parties to reproduce this material.

\section{Consent for publication}

Written informed consent has been provided by the patient's father. And the father gave us full permission for the materials to appear in the print and online, and grant permission to third parties to reproduce this material.

\section{Competing interests}

The authors declare that they have no conflict of interest.

\section{Author details}

${ }^{1}$ Department of Orthopedics, West China Hospital, Sichuan University, 37 Guo Xue Lane, 610064 Chengdu, Sichuan, People's Republic of China. ${ }^{2}$ Department of Orthopedics, People's Fourth Hospital of Sichuan Province, Chengdu, Sichuan, People's Republic of China. ${ }^{3}$ Department of Vascular Surgery, West China Hospital, Sichuan University, Chengdu, Sichuan, People's Republic of China.

Received: 30 June 2020 Accepted: 13 August 2020

Published online: 19 August 2020

\section{References}

1. Lee A, Driscoll D, Gloviczki P, Clay R, Shaughnessy W, Stans A. Evaluation and management of pain in patients with Klippel-Trenaunay syndrome: a review. Pediatrics. 2005;115(3):744-9.

2. Al-Najjar RM, Fonseca R. An atypical case of Klippel-Trénaunay syndrome presenting with crossed-bilateral limb hypertrophy and postaxial polydactyly: a case report. BMC Pediatr. 2019;19(1):95.

3. Horbach SE, Lokhorst MM, Oduber CE, Middeldorp S, van der Post JA, van der Horst CM. Complications of pregnancy and labour in women with Klippel-Trénaunay syndrome: a nationwide cross-sectional study. BJOG: an international journal of obstetrics gynaecology. 2017;124(11):1780-8.

4. Klippel M, Trenaunay P. Naevus variqueux Osteohypertrophique. Arch Gen Med. 1900;14:65-70.

5. Opdenakker O, Renson T, Walle JV. Vesical Hemangioma in a Patient with Klippel-Trenaunay-Weber Syndrome. The Journal of Pediatrics. 2019;208: 293-3.e292.

6. Luks VL, Kamitaki N, Vivero MP, Uller W, Rab R, Bovée JV, Rialon KL, Guevara CJ, Alomari Al, Greene AK, et al. Lymphatic and other vascular malformative/ overgrowth disorders are caused by somatic mutations in PIK3CA. J Pediatr. 2015, 166(4):1048-1054.e1041-1045

7. Sepulveda A, Soriano H, Espino A. Gastrointestinal tract involvement in Klippel-Trénaunay syndrome. The lancet Gastroenterology hepatology. 2018; 3(7):518.

8. Oduber CEU, Horst CMAMvd, Hennekam RCM. Klippel-Trenaunay Syndrome: Diagnostic Criteria and Hypothesis on Etiology. Ann Plast Surg. 2008;60(2): 217-23.

9. Noel AA, Gloviczki P, Cherry KJ, Rooke TW, Stanson AW, Driscoll DJ. Surgical treatment of venous malformations in Klippel-Trénaunay syndrome. J Vasc Surg. 2000;32(5):840-7. 
10. Boon LM, Mulliken JB, Vikkula M. RASA1: variable phenotype with capillary and arteriovenous malformations. Curr Opin Genet Dev. 2005;15(3):265-9.

11. Boutarbouch M, Ben Salem D, Giré L, Giroud M, Béjot Y, Ricolfi F. Multiple cerebral and spinal cord cavernomas in Klippel-Trenaunay-Weber syndrome. Journal of clinical neuroscience: official journal of the Neurosurgical Society of Australasia. 2010;17(8):1073-5.

12. Timur AA, Driscoll DJ, Wang Q. Biomedicine and diseases: the KlippelTrenaunay syndrome, vascular anomalies and vascular morphogenesis. Cell Mol Life Sci. 2005;62(13):1434-47.

13. John PR. Klippel-Trenaunay Syndrome. Tech Vasc Interv Radiol. 2019;22(4): 100634.

14. Jacob AG, Driscoll DJ, Shaughnessy WJ, Stanson AW, Clay RP, Gloviczki P. Klippel-Trénaunay syndrome: spectrum and management. Mayo Clin Proc. 1998, 73(1):28-36.

15. Gloviczki P, Driscoll DJ. Klippel-Trenaunay syndrome: current management. Phlebology. 2007;22(6):291-8.

16. Wang SK, Drucker NA, Gupta AK, Marshalleck FE, Dalsing MC. Diagnosis and management of the venous malformations of Klippel-Trénaunay syndrome. J Vasc Surg Venous Lymphat Disord. 2017;5(4):587-95.

17. Kundzina L, Lejniece S. Klippel-Trenaunay-Weber syndrome with atypical presentation of hypersplenism and nephrotic syndrome: a case report. J Med Case Rep. 2017;11(1):243.

18. Karadag A, Senoglu M, Sayhan S, Okromelidze L, Middlebrooks EH. KlippelTrenaunay-Weber Syndrome with Atypical Presentation of Cerebral Cavernous Angioma: A Case Report and Literature Review. World Neurosurg. 2019;126:354-8.

19. Zhang J, Wang K, Mei J. Late puerperal hemorrhage of a patient with Klippel-Trenaunay syndrome: A case report. Medicine. 2019;98(50):e18378.

20. Redondo P, Bastarrika G, Aguado L, Martínez-Cuesta A, Sierra A, Cabrera J, Alonso-Burgos A. Foot or hand malformations related to deep venous system anomalies of the lower limb in Klippel-Trénaunay syndrome. J Am Acad Dermatol. 2009;61(4):621-8.

21. McGrory BJ, Amadio PC, Dobyns JH, Stickler GB, Unni KK. Anomalies of the fingers and toes associated with Klippel-Trenaunay syndrome. The Journal of bone joint surgery American volume. 1991:73(10):1537-46.

22. Wu JS, Hochman MG. Bone Tumors: A Practical Guide to Imaging. New York: Springer; 2012

23. Lezama-del Valle P, Gerald WL, Tsai J, Meyers P, La Quaglia MP. Malignant vascular tumors in young patients. Cancer. 1998;83(8):1634-9.

24. Mathews MS, Kim RC, Chang GY, Linskey ME. Klippel-Trenaunay syndrome and cerebral haemangiopericytoma: a potential association. Acta Neurochir (Wien). 2008, 150(4):399-402.

25. Howitz P, Howitz J, Gjerris F. A variant of the Klippel-Trenaunay-Weber syndrome with temporal lobe astrocytoma. Acta Paediatr Scand. 1979;68(1): $119-21$.

26. Ploegmakers MJM, Pruszczynski M, De Rooy J, Kusters B, Veth RPH. Angiosarcoma with malignant peripheral nerve sheath tumour developing in a patient with klippel-trénaunay-weber syndrome. Sarcoma. 2005;9(3-4): $137-40$

27. Spallone A, Tcherekayev VA. Simultaneous occurrence of aneurysm and multiple meningioma in Klippel-Trenaunay patients: case report. Surg Neurol. 1996:45(3):241-4.

28. van der Loo LE, Beckervordersandforth J, Colon AJ, Schijns OEMG. Growing skull hemangioma: first and unique description in a patient with KlippelTrénaunay-Weber syndrome. Acta Neurochir (Wien). 2017;159(2):397-400.

29. Greene AK, Kieran M, Burrows PE, Mulliken JB, Kasser J, Fishman SJ. Wilms Tumor Screening Is Unnecessary in Klippel-Trenaunay Syndrome. Pediatrics. 2004;113(4):e326.

30. Blatt J, Finger M, Price V, Crary SE, Pandya A, Adams DM. Cancer Risk in Klippel-Trenaunay Syndrome. Lymphat Res Biol. 2019;17(6):630-6.

31. Rao A, Rothman J, Nichols KE. Genetic testing and tumor surveillance for children with cancer predisposition syndromes. Curr Opin Pediatr. 2008; 20(1):1-7.

\section{Publisher's Note}

Springer Nature remains neutral with regard to jurisdictional claims in published maps and institutional affiliations.

\section{Ready to submit your research? Choose BMC and benefit from:}

- fast, convenient online submission

- thorough peer review by experienced researchers in your field

- rapid publication on acceptance

- support for research data, including large and complex data types

- gold Open Access which fosters wider collaboration and increased citations

- maximum visibility for your research: over $100 \mathrm{M}$ website views per year

At $\mathrm{BMC}$, research is always in progress.

Learn more biomedcentral.com/submissions 